\title{
Clinical Treatment of Pathological Scar: Current Situation and Future Trend
}

\author{
Rujin $\mathrm{Li}^{1}$, Xin Cheng ${ }^{1}$, Xunzhou Yu*2,3 and Qing Zhang*3 \\ ${ }^{1}$ The Fifth People's Hospital of Huangshi City, China \\ ${ }^{2}$ Chinese People's Liberation Army, China
}

${ }^{3}$ State Key Laboratory of Trauma, Burns and Combined Injuries, China

Received: 制: December 31, 2018; Published: 制: January 10, 2019

*Corresponding author: Xunzhou Yu, Chinese People's Liberation Army, 89th Hospital, Weifang, Shandong, China

Qing Zhang, Institute of Burn Research, State Key Laboratory of Trauma, Burns and Combined Injuries, Southwest Hospital, Chongqing China

\begin{abstract}
Abnormal wound healing is most likely to induce scar formation. The large amount of deposition of collagen-based extracellular matrix and the excessive proliferation of dermal tissue give rise to dysfunction, deformity and psychological trauma in burn patients with pathological scar. The complex pathogenesis of pathological scar makes scar healing remains a challenge without an ideal cure way. Here, the clinical treatment experiences and research results of pathological scar were reviewed, and a novel therapeutic strategy based on soluble polymeric microneedles currently being on our radar, which seems to be a perfect solution for home-based treatment of scars.
\end{abstract}

Keywords: Wound Healing; Pathological Scar; Clinical Treatment; Polymeric Microneedles; Home Based Treatment

\section{Introduction}

Following injury such as burn, surgery and anabrosis, normal skin may undergo morphological and histopathological changes, so that scarring is an inevitable outcome of wound repair, which is the manifestation human's self-defense, while excessive scarring should be regarded as morbidity [1-4]. Pathological scar is concerned to be one of the most common complication after burn and traumas. Scarring of the appearance and dysfunction, in some severe cases, bring great physical and psychological burden to patients [5-7]. Therefore, the pathogenesis of formation, prevention and treatment of scar are becoming the clinical focus in the surgery department. Though the precise pathogenesis of excessive scarring has not been fully understood, in recent years, researchers have gradually explored the formation and regression mechanism of pathological scar from different perspectives and obtained a relatively consistent views: Pathological scar is characterized by the increased inflammatory, proliferation of myofibroblasts and disorder of collagen metabolism caused excessive extracellular matrix (ECM) deposition. TGF- beta $1 /$ smad signaling pathway is also closely related to these excessively scarring lesions [5, 8-10]. Based on the known pathogenesis, Regulating the proliferation, differentiation, migration and apoptosis of myofibroblast, collagen metabolism and arrangement, and other relevant signal pathways are main effective approaches for scar treatment [11-13].

\section{Current Treatment Strategies}

Currently, surgical excision, pressure, radiation therapy, chemotherapy, and other medication surgical treatments are the major therapy strategies. In the latest Chinese expert consensus on clinical prevention and treatment of scar and other review literatures, the available clinical therapies including topical preparations with onion-extract, mitomycin C, and imiquimod. Intralesional injections with bleomycin, corticosteroids, and 5-fluorouracil. Pressure therapy with silicone gel, and hypoallergenic microporous tape. Radiotherapy with radiofrequency ablation. Photodynamic therapy with intensive pulsed light, pulsed dye laser, and fractional laser. And cryotherapy, surgery, as well [3,6,9,14-17]. Moreover, there were reports about intra-lesional injections of collagenase, [11] botulinum toxin-A, [12] stem cell therapym [18] and autologous chyle fat grafting [19] for the treatment of hypertrophic scars.

However, these monotherapies remain unsatisfactory therapeutic effect due to their defects such as pain, drug side effects, radiogenic cancer risks, low transdermal efficiency, 
ulceration, [9] and because of the complexity of scarring mechanism and persistently evolving process [3]. So far, available clinical experiences and experimental-based data have suggested that a combination approach is more effective, using multiple modalities of therapy strategies (e.g., the combination of onion extract preparations and silicone gel sheet, [20] or triamcinolone acetonide, [14] CO2 fractional laser combined with 5-florouracil [21]. But the optimal combination therapy is still to be investigated and determined depending on the individual case.

\section{New Microneedles-Based Approach}

Polymeric microneedles (MNs) are emerging as an excellent transdermal delivery system to overcome the limitations of conventional needle injection, owing to it allows both macro and micro-molecules traversing the stratum corneum in a minimally invasive way and even controlled release, and further can be conveniently self-administered by patients [22-25]. During the last year, amounts of studies have worked on this feasible technique for the effective transdermal administration of drugs and tried to promote research of MNs trend to market applications [26-28]. The successful clinical use of the microneedle in vaccine therapy inspired our group to realize that self-administered MNs appeared to be an attractive alternative method for clinical treatment of scars. Meantime, we noticed that Liu's group have trie to apply peptideloaded microneedles to a keloid scar model and demonstrated a potential therapeutic effect [29].

\section{Conclusion}

With the development of clinical technologies and patients' growing desire to improve the treatment process, a trend is currently observed toward the indication of less invasive isolated or combined techniques in the treatment of scars. Thus emerging novel therapeutic approaches including microneedles-based strategy need more research to enable the improvement of strategies on scar management.

\section{References}

1. Gangemi EN, Gregori D, Berchialla P, Zingarelli E, Cairo M, et al. (2008) Epidemiology and Risk Factors for Pathologic Scarring After Burn Wounds. Archives of Facial Plastic Surgery 10(2): 93-102.

2. Velnar T, Bailey T, Smrkolj V (2009) The wound healing process: an overview of the cellular and molecular mechanisms. Journal of international medical research 37(5): 1528-1542.

3. Lv K, Xia Z (2018) Chinese expert consensus on clinical prevention and treatment of scar. Burns Trauma 6: 27-36.

4. Ogawa R (2018) Recent Advances in Scar Biology. Int J Mol Sci 19(6): 1749-1753.

5. Finnerty CC, Jeschke MG, Branski LK, Barret JP, Dziewulski P, et al. (2016) Hypertrophic scarring: the greatest unmet challenge after burn injury. Lancet 388(10052): 1427-1436.

6. Gauglitz GG, Korting HC, Pavicic T, Ruzicka T, Jeschke MG (2011) Hypertrophic scarring and keloids: pathomechanisms and current and emerging treatment strategies. Mol Med 17(1-2): 113-125.

7. Tziotzios C, Profyris C, Sterling J (2012) Cutaneous scarring: Pathophysiology, molecular mechanisms, and scar reduction therapeutics Part II. Strategies to reduce scar formation after dermatologic procedures. J Am Acad Dermatol 66(1): 13-26.

8. Profyris C, Tziotzios C, Do Vale I (2012) Cutaneous scarring: Pathophysiology, molecular mechanisms, and scar reduction therapeutics Part I. The molecular basis of scar formation. J Am Acad Dermatol 66(1): 1-10.

9. Lee HJ, Jang YJ (2018) Recent Understandings of Biology, Prophylaxis and Treatment Strategies for Hypertrophic Scars and Keloids. Int J Mol Sci 19(3): 711-730.

10. Tan J, Wu J (2017) Current progress in understanding the molecular pathogenesis of burn scar contracture. Burns Trauma 5: 14-20.

11. Kang N, Sivakumar B, Sanders R, Nduka C, Gault D (2006) Intra-lesional injections of collagenase are ineffective in the treatment of keloid and hypertrophic scars. J Plast Reconstr Aesthet Surg 59(7): 693-699.

12. Honeybrook A, Lee W, Woodward J, Woodard C (2018) Botulinum Toxin-A and Scar Reduction: A Review. The American Journal of Cosmetic Surgery 35(4): 165-176.

13. Li J, Cen B, Chen S, He Y (2016) MicroRNA-29b inhibits TGF-beta1induced fibrosis via regulation of the TGF-beta1/Smad pathway in primary human endometrial stromal cells. Mol Med Rep 13(5): 42294237.

14. Koc E, Arca E, Surucu B, Kurumlu Z (2008) An open, randomized, controlled, comparative study of the combined effect of intralesional triamcinolone acetonide and onion extract gel and intralesional triamcinolone acetonide alone in the treatment of hypertrophic scars and keloids. Dermatol Surg 34(11): 1507-1514.

15. Li P, Li Tsang CWP, Deng X, Wang X, Wang H, et al. (2018) The recovery of post-burn hypertrophic scar in a monitored pressure therapy intervention programme and the timing of intervention. Burns 44(6): 1451-1467.

16. Viera MH, Amini S, Valins W, Berman B (2010) Innovative therapies in the treatment of keloids and hypertrophic scars. Journal of Clinical and Aesthetic Dermatology 3(5): 20-26.

17.Zuccaro J, Ziolkowski N, Fish J (2017) A Systematic Review of the Effectiveness of Laser Therapy for Hypertrophic Burn Scars. Clin Plast Surg 44(4): 767-779.

18. Cheng JZ, Farrokhi A, Ghahary A, Jalili RB (2018) Therapeutic Use of Stem Cells in Treatment of Burn Injuries. J Burn Care Res 39(2): 175182.

19. Xu X, Lai L, Zhang X, Chen J, Chen J, et al. (2018) Autologous chyle fat grafting for the treatment of hypertrophic scars and scar-related conditions. Stem Cell Res Ther 9(1): 64.

20. Hosnuter M, Payasli C, Isikdemir A, Tekerekoglu B (2007) The effects of onion extract on hypertrophic and keloid scars. Journal of Wound Care 16(6): 251-255.

21. Zhang Z, Chen J, Huang J, Wo Y, Zhang Y, et al. (2018) Experimental Study of 5-fluorouracil Encapsulated Ethosomes Combined with CO2 Fractional Laser to Treat Hypertrophic Scar. Nanoscale Res Lett 13(1): 26.

22. Wang M, Hu L, Xu C (2017) Recent advances in the design of polymeric microneedles for transdermal drug delivery and biosensing. Lab Chip 17(8): 1373-1387.

23. Lim DJ, Vines JB, Park H, Lee SH (2018) Microneedles: A versatile strategy for transdermal delivery of biological molecules. Int J Biol Macromol 110: 30-38.

24. Choi IJ, Aram Kang, Myun Hwan Ahn, Hyesun Jun, Seung Ki Baek, et al. (2018) Insertion-responsive microneedles for rapid intradermal delivery of canine influenza vaccine. J Control Release 286: 460-466. 
25. Zhang Y, Peijian Feng, Jicheng Yu, Jia Yang, Jiacheng Zhao, et al. (2018) ROS-Responsive Microneedle Patch for Acne Vulgaris Treatment. Advanced Therapeutics 1(3): 1800035.

26. Nguyen TT, Park JH (2018) Human studies with microneedles for evaluation of their efficacy and safety. Expert Opin Drug Deliv 15(3): 235-245.

27. Migdadi EM, Courtenay AJ, Tekko IA, McCrudden MTC, Kearney MC, et al. (2018) Hydrogel-forming microneedles enhance transdermal delivery of metformin hydrochloride. J Control Release 285: 142-151.

\section{ISSN: 2574-1241}

DOI: 10.26717/BJSTR.2019.13.002336

Xunzhou Yu, Qing Zhang. Biomed J Sci \& Tech Res

(C) (P) This work is licensed under Creative

Submission Link: https://biomedres.us/submit-manuscript.php
28. Nejad HR, Sadeqi A, Kiaee G, Sonkusale S (2018) Low-cost and cleanroomfree fabrication of microneedles. Microsystems \& Nanoengineering 4: 17073.

29. Liu S, David C Yeo, Christian Wiraja, Hong Liang Tey, Milan Mrksich et al. (2017) Peptide delivery with poly (ethylene glycol) diacrylate microneedles through swelling effect. Bioeng Transl Med 2(3): 258-267.

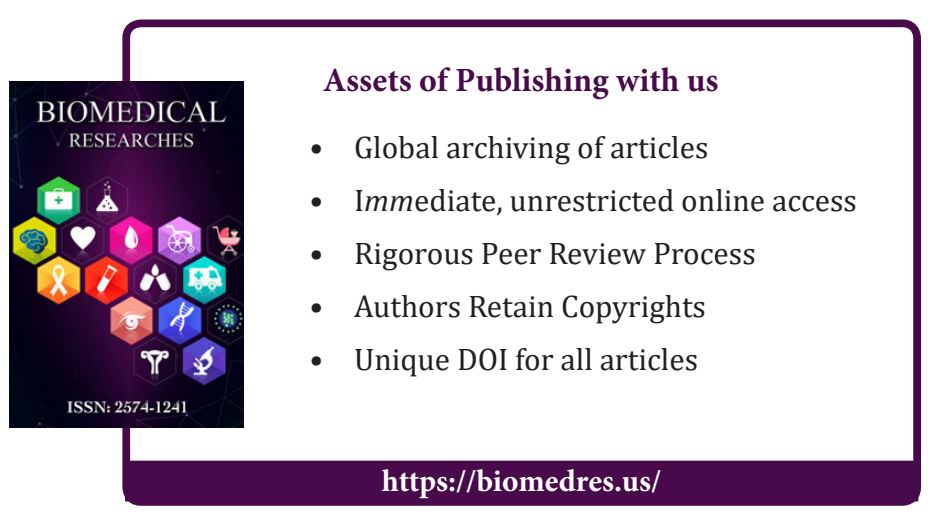

